\title{
LEI ROUANET X CROWDFUNDING: FOMENTANDO OS EMPREENDIMENTOS CULTURAIS
} ROUANET LAW X CROWDFUNDING: PROMOTING THE CULTURAL VENTURES

Recebido em 29.05.2014. Aprovado em 12.05.2015 Avaliado pelo sistema double blind review DOI: http://dx.doi.org/10.12712/rpca.v9i2.457

\section{Clerilei Aparecida Bier}

clerilei.bier@udesc.br

Universidade do Estado de Santa Catarina - UDESC, Florianópolis/SC, BRASIL

\author{
Ricardo Alves Cavalheiro \\ tatocavalheiro@gmail.com \\ Universidade do Estado de Santa Catarina - UDESC, Florianópolis/SC, BRASIL
}

\section{Resumo}

O presente trabalho objetiva analisar os métodos de captação de recursos de empreendimentos culturais da Lei Rouanet e do Crowdfunding. A estratégia de investigação utilizada foi a de estudo multicasos, de cunho predominantemente qualitativo e descritivo, em uma visão contextual-processual, utilizando-se do método de investigação histórico-interpretativo. Embasado no resultado da pesquisa, propôs-se uma plataforma de financiamento cultural direcionada às pessoas físicas capaz de promover a emancipação da sociedade civil, no que tange a tomada das rédeas da produção cultural nacional, em especial na definição dos destinos de aplicação tanto dos recursos públicos quanto da efetivação das políticas culturais brasileiras. Dita plataforma se propõe ainda potencializar as políticas públicas culturais, bem como democratizar o processo decisório da alocação dos recursos públicos do Estado Brasileiro com participação e controle social, em harmonia com a Lei Rouanet.

Palavras-chave: Direitos Culturais. Políticas Públicas Culturais. Lei Rouanet. Crowdfunding.

\section{Abstract}

This study aims to analyze the methods of fundraising cultural initiatives of the Rouanet Law and Crowdfunding. The research strategy used was the multi-case study of predominantly qualitative approach and descriptive, in a context-process view, using the method of historical-interpretive research. Based upon the results of the research, we proposed a platform for cultural funding directed to individuals able to promote the emancipation of civil society when it comes to taking the reins of the national cultural production, in particular by defining the destinations of both application resource public and the effectiveness of Brazilian cultural policies. This platform proposes further enhance public cultural policies and democratize decision-making process the allocation of public resources of the Brazilian State participation and social control, in harmony with the Rouanet Law.

Keywords: Cultural Rights. Public Policy Cultural Rouanet. Crowdfunding. 


\section{Introdução}

A cultura exprime originalidade, pluralidade e tolerância de uma sociedade. Também considerada a função mais fecunda, a cultura pode ser entendida como o conjunto de valores, hábitos, influências sociais e costumes reunidos ao longo do tempo. Em outras palavras, a cultura abrange tudo o que com o passar do tempo se incorpora à vida dos indivíduos, impregnando o seu cotidiano e contribuindo para o progresso do progresso (AZEVEDO, 1971; FREYRE, 1969; MOLES, 1974).

Em todo o globo, é possível reconhecer diferentes processos de legitimação e proteção do exercício e do acesso à cultura e aos bens culturais. Nesse sentido, observa-se que o amparo ao direito cultural encontra respaldo no berço dos direitos humanos, os quais são um conjunto de princípios fundamentais e normas acordadas internacionalmente, propostos para reger o comportamento humano e garantir às pessoas sua sobrevivência com dignidade e segurança econômica, social e cultural (FERNÁNDEZ, 2011; MACHADO, 2011).

A postura governamental brasileira não é alheia a esta realidade. A Constituição Brasileira de 1988 consagrou o princípio da cidadania cultural como direito fundamental, ou seja pertencentes aos valores jurídicopolíticos que se originam da dignidade inerente a todo ser humano e que estão ligados às suas potencialidades. Ademais, no Brasil a proteção ao exercício e acesso a cultura passam a implementar-se através de Políticas Publicas voltadas ao fomento da cultura. Neste diapasão, o estado brasileiro busca com leis de fomento à cultura, com o Plano Nacional de Cultura e com o Sistema Nacional de Cultura e a Lei Rouanet dar corpo à Política Pública direcionada às diversas demandas apresentadas pelo setor cultural brasileiro.

Nesse contexto, destaca-se que a manifestação cultural brasileira é expressiva tanto em termos financeiros quanto no número absoluto de pessoas envolvidas na cadeia produtiva cultural. Isso, pois, segundo os dados da FIRJAN (2014), afere-se que a Economia Criativa brasileira é composta por 251 mil empresas que empregam 892,5 mil trabalhadores. Além de apresentar um crescimento de 69,1\% desde 2004. Com base na massa salarial destas empresas, estima-se que a indústria criativa brasileira gere um Produto Interno Bruto equivalente a $\mathrm{R} \$ 126$ bilhões, ou 2,6\% do total produzido no Brasil em 2013. Destaca-se ainda, que desde 2004, o PIB da Indústria Criativa avançou
69,8\% em termos reais, acima do avanço de $36,4 \%$ do PIB brasileiro nos mesmos dez anos (FIRJAN, 2014).

Diante do exposto, o presente estudo se propôs analisar duas formas de financiamento de empreendimentos presentes no campo da Economia Criativa brasileira, no intuito de contribuir para a melhoria do processo de financiamento da cadeia produtiva cultural nacional, quais sejam Lei Rouanet e Crowdfunding.

No primeiro momento, buscou-se levantar e comparar os pontos de sucesso e insucesso do método tradicional advindo da Lei Rouanet, enquanto Política Pública Cultural de afirmação e promoção dos direitos culturais. A continuação analisou-se a metodologia Crowdfunding, contemporânea do novo paradigma tecnológico-social resultante da revolução vivida nas últimas décadas.

Inicia-se pela analise da Lei 8.313 de 1991 que instituiu o Programa Nacional de Apoio à Cultura, nacionalmente conhecida como Lei Rouanet, integrante do arcabouço legal brasileiro, como instrumento de política cultural. O referido mecanismo de incentivos fiscais é um instrumento de fomento ao setor cultural que propicia o abatimento de parte do imposto sobre a renda de pessoas físicas e jurídicas em prol de projetos culturais certificados pelo Ministério da Cultura.

Não obstante, ainda que a Lei Rouanet represente um marco significativo na história do fomento cultural nacional e que alcance cifras expressivas, observamse muitas restrições na implementação das práticas previstas nas diretrizes legais. Percebe-se, ainda, uma tendência de monopólio do financiamento das atividades culturais de reconhecido prestígio por grandes grupos empresariais em detrimento de inúmeros projetos culturais que não possuem apelo comercial, ou não são executados por artistas renomados, que acabam por não conseguir captar recursos. (CESNIK, 2007; LIMA, 2004; WU, CHINTAO, 2006; ALVES, 2011).

Diante dessas dificuldades de financiamento de projetos culturais com baixo apelo comercial, bem como frente às oportunidades advindas do uso intensivo de tecnologia da informação, surge o Crowdfunding como metodologia complementar de levantamento de fundos para a viabilização de projetos culturais. Utilizando-se de plataformas de organizações virtuais, o Crowdfunding é entendido como o processo de um financiamento coletivo de um projeto, em que 
se solicita e recebe pequenas contribuições de muitos financiadores, em troca de uma forma de recompensa a esses apoiadores (HOWE, 2006; RUBINTON, 2011).

Para tanto, o Crowdfunding se utiliza do convite, através da Internet, no levante de recursos financeiros seja em forma de doação, troca do produto futuro ou alguma forma de recompensa que pode ser monetária. Com isso, os empreendedores podem "postar" o seu projeto na plataforma e beneficiar de visibilidade da plataforma para chegar a potenciais investidores (BELLEFLAMME; LAMBERT e SCHWIENBACHER, 2011). Nesse ínterim, as plataformas de Crowdfunding permitem aos usuários a possibilidade de realizar investimentos em vários tipos de projetos e empreendimentos, muitas vezes, em pequenas quantidades, fora de uma bolsa regulada, usando plataformas de mídia social on-line que facilitam a interação direta entre os investidores (AGRAWAL, CATALINI E GOLDFARB, 2011).

Destaca-se, ainda, que de acordo com Crowdsourcing. org (2013), até o final do ano de 2013, mais de 450 plataformas de Crowdfunding operavam por todo o globo. Em conjunto, essas levantaram quase US\$ 5,1 bilhão e financiaram com êxito mais de um milhão de projetos. No Brasil, os números também surpreendem, haja vista que a plataforma brasileira de Crowdfunding, Catarse.me, já levantou, desde 2010, R \$ 4.771.134,00, destinados a 361 projetos bem sucedidos, apoiados por 45.077 pessoas. Além disso, a plataforma Catarse.

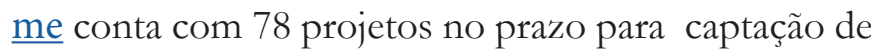
recursos, até o momento da redação final do presente estudo.

Diante disso, acredita-se, que a utilização de organizações virtuais de Crowdfunding pode mudar a dinâmica de fomento cultural no país, ao abrir um novo canal para a captação de doações e patrocínios viabilizados pela Lei Rouanet, bem como proporcionar um novo horizonte de participação social na gestão da aplicação dos recursos públicos.

Em razão ao exposto, e como resultado do estudo realizado, propõe-se uma plataforma de financiamento cultural que pode ser uma nova oportunidade para que a sociedade civil se insira como verdadeiro agente de divulgação, promoção e legitimação do processo de fomento à cultura nacional. Através do exercício de cidadania e articulação artística, pode a mesma construir uma nova realidade que se refletirá na reorganização e democratização das políticas publicas culturais do Estado brasileiro.

\section{Procedimentos metodológicos}

Considerando-se o objetivo do presente trabalho, este estudo caracteriza-se como de natureza exploratóriadescritiva e avaliativa, ao analisar o processo de financiamento de empreendimentos culturais que está compreendido na intersecção de diversas áreas do conhecimento tais como direito tributário, políticas públicas, empreendedorismo cultural e organizações virtuais, com perspectiva de analise qualitativa. Sua perspectiva do estudo é diacrônica e o método utilizado é o histórico interpretativo, enquanto que o modo de investigação que fundamenta o presente estudo se identifica como estudo casos múltiplos.

A unidade de análise geral é processo de captação de recursos financiadores de empreendimentos culturais, constituído como entidade. Esta entidade é o "caso" a partir do qual a proposição do estudo é analisada, no intuito de se obter melhores informações e formas mais consistentes. A pesquisa incorporou dois métodos de captação de recursos, fato que a qualifica como estudo de casos múltiplos.

As técnicas de coleta de dados utilizadas são a pesquisa bibliográfica, entrevista não estruturada, análise documental e a observação participante. Utilizaram-se as entrevistas não estruturadas em conversas informais com empreendedores culturais (curadores de museus, artistas plásticos, produtores culturais, espectadores, colecionadores, consumidores, empresários etc.), no intuito de levantar os valores atribuídos a determinadas questões, tais como o processo de fomento à cultura brasileira, de construção de políticas públicas culturais no território nacional A análise documental se dá nos arquivos da União, bem como no acervo nacional e internacional de publicações científicas relativas aos objetivos propostos, arquivos históricos, periódicos, registros estatísticos, diários, jornais, internet, revistas eletrônicas, relatórios institucionais internacionais, nos quais se levantaram os principais pontos de sucesso e insucesso das atuais plataformas de captação de recursos de incentivos fiscais brasileiras. (AMBONI, 1997, DENZIN; LINCOLN, 2006; SILVA; GODOI; MELLO, 2006, RICHARDSON, 1999).

Por fim, analisaram-se os dois métodos de captação sob a luz do modelo de Petitgrew (1987) que fomenta as formas de pesquisa que considerem os caracteres contextuais, processuais e históricos. A continuação apresenta-se uma reflexão capaz de compatibilizar as demandas de captação de recursos junto às pessoas físicas e jurídicas, advindos da renúncia fiscal viabilizada 
pela Lei Rouanet, com a dinâmica do Crowdfunding. Tal reflexão embasa a propositura de um possível modelo em que as organizações virtuais possam potencializar as políticas públicas culturais, assim como contribuir para o fomento, a distribuição e o acesso das pessoas físicas aos empreendimentos culturais, em harmonia com a Lei Rouanet.

Ressalte-se que foram analisados o conteúdo, o contexto externo e interno, bem como processo de mudança, de forma longitudinal (AMBONI, 1997; PETTIGREW, 1987). Com isso, buscou-se apresentar, de modo sintético, os principais pontos históricos ao longo tanto da formulação do instrumento de Política Pública Cultural quanto do surgimento do fenômeno do Crowdfunding relativos aos empreendimentos culturais brasileiros.

\section{Análise comparativa dos métodos de captação e proposta de modelo alternativo}

No presente momento, o estudo iniciará a análise comparativa das diferentes formas de financiamento de empreendimentos culturais, no intuito de embasar a propositura de um possível modelo em que as organizações virtuais possam potencializar as políticas públicas culturais, assim como contribuir para o fomento, a distribuição e o acesso das pessoas físicas aos empreendimentos culturais, em harmonia com a Lei Rouanet.

Para tanto, utilizar-se-á como ferramenta da análise comparativa de cada método de financiamento o procedimento de Pettigrew (1987), uma vez que a referida técnica procura conceitualizar as maiores transformações das organizações nas ligações entre o conteúdo da mudança, o contexto e processo, em um complexo, analítico, político e cultural do processo de mudança, na estrutura e na estratégia dos financiamentos de empreendimentos culturais.

De acordo com Pettigrew (1987) uma pesquisa de caráter contextual e processual explica as características emergentes, situacionais e holísticas de um organismo ou processo em seu contexto de transformação. Nessa seara, para entender a mudança, segundo Pettigrew (1987), deve-se examinar a justaposição do analítico e do político, bem como o papel das pessoas de destaque e as circunstâncias extremas, quando suas habilidades são testadas pelas forças da interação com às forças positivas e as restritivas do ambiente.

Nesse sentido, cabe ressaltar que foram analisados o conteúdo, o contexto externo e interno, bem como processo de mudança, de forma longitudinal. Com isso, buscou-se apresentar, de modo sintético, os principais pontos históricos ao longo tanto da formulação do instrumento de Política Pública Cultural quanto do surgimento do fenômeno do Crowdfunding relativos aos empreendimentos culturais brasileiros.

Figura 1 - Dinâmica dos métodos de financiamento cultural sob a luz do Modelo de Pettigrew (1987).

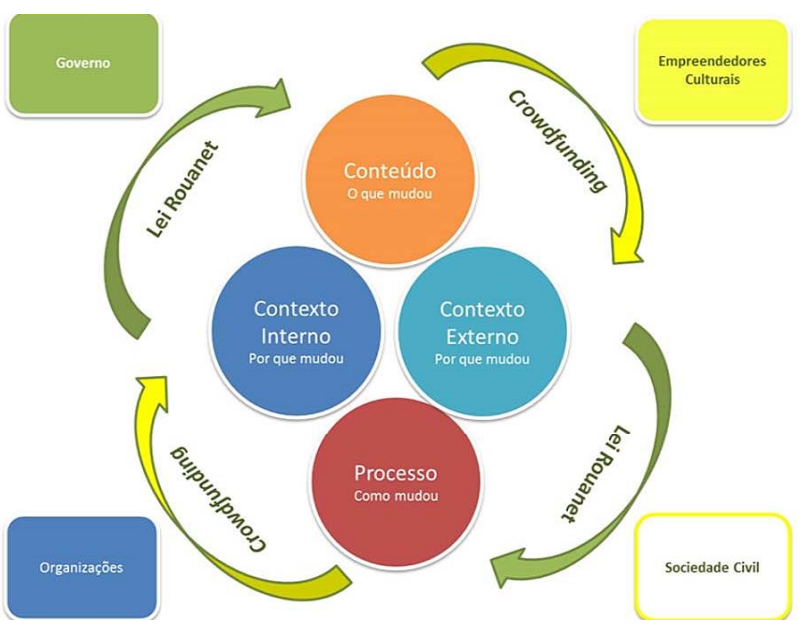

Fonte: Elaborada pelos autores.

Ademais, na análise horizontal, arbitram-se como elementos de distintos níveis estratégicos: o Estado, os Empreendedores culturais, a Organizações e a Sociedade. Sendo assim, o nível estratégico "Estado", dever-se-á interpelá-lo pela ação das esferas legislativa, administrativa e judicial do Estado Brasileiro. Isso porque, entende-se que toda política pública deve seguir o devido processo legal para ser legitima e aplicável no estado democrático de direito brasileiro.

Já o nível estratégico "Empreendedores Culturais" é entendido como aquele que engloba os trabalhadores e organizações da cadeia produtiva da economia criativa brasileira. Estão, portanto, contidos todos os agentes, mediadores, gestores, administradores, produtores e captadores de recursos, sejam esses pessoas físicas ou jurídicas que atuam na viabilização dos empreendimentos culturais.

No nível estratégico denominado "Organizações", estão representadas todas as pessoas jurídicas que, apesar de não ter como objetivo fim a produção cultural, apoiam a cultura nacional financeiramente ou de forma institucional.

Por fim, o nível estratégico "Sociedade Civil", deve ser entendido como a forma genérica de atuação de 
parte dos cidadãos brasileiros beneficiados direta ou indiretamente pela produção cultural do Brasil.

Destaca-se que a opção de seccionar os níveis deste modo, pauta-se em objetivo meramente didático, pois não se pretende demonstrar com precisão cirúrgica as diversas ramificações sociais-brasileira, mas sim ajudar a compreender os diferentes níveis de interações entre alguns setores envolvidos na cadeia produtiva da economia cultural nacional.

\section{Financiamento aos empreendimentos culturais via Lei Rouanet}

É cediço que, diante da história da instrumentalização de políticas culturais no Brasil, apesar da significância do movimento cultural brasileiro, segundo Almeida (1993), é só a partir da década de 30 que arte e poder convergem conceitualmente no território brasileiro. Nesse seara, o nacionalismo associado ao desenvolvimento ganha especial relevo nas décadas seguintes, extrapolando a era getulista e desaguando nos anos 60. A despeito dessa circunstância, a partir da gestão Geisel, são criadas e abastecidas com verbas generosas diversas agências de fomento à produção como a Funarte e a Embrafilme, além de institutos específicos (ALMEIDA, 1993).

Nos anos oitenta, com o governo Sarney, sinalizou-se a consolidação do setor com a criação do Ministério da Cultura, capitaneado por Celso Furtado, ao qual seguiu-se uma série de leis federais de leis de incentivo fiscal sob o fulcro de estimular a participação do setor privado no setor cultural brasileiro, tal como a Lei Sarney (Lei 7.505/86), oriunda de um projeto de lei apresentada em 1975.

O governo Collor, por sua vez, implodiu o sistema, extinguindo o Ministério da Cultura e as leis de incentivo. (VALIATI e FLORISSI, 2005). De acordo com Carvalho (2009), o objetivo declarado era a contenção dos gastos públicos, num quadro econômico instável, o que de fato aconteceu ao ser reduzido o orçamento federal para a cultura em mais de $50 \%$ em relação ao período anterior, fato que foi agravado pela desativação da Lei Sarney.

Destaca-se ademais, que a sociedade civil não foi consultada em toda essa convulsão, mas resistiu ao desmonte institucional ao exigir, de múltiplas formas, a recomposição dos instrumentos políticos obtidos anos antes, o que levou à formulação, em 1991, do instrumento substitutivo da Lei Sarney (CARVALHO, 2009). Sob o governo do Presidente Itamar Franco, o então secretário da Cultura Luis Paulo Rouanet promoveu uma revisão da Lei Sarney, redefinindo os incentivos concedidos e o sistema para aprovação de projetos, culminando então na chamada Lei Rouanet (Lei n 8.313/1991) além de criar o Fundo Nacional de Cultura, órgão de investimento público direto a fundo perdido, ambos perdurando até o período atual.

De acordo com as informações oficias do governo brasileiro (BRASIL, 2014), o mecanismo de incentivos fiscais da Lei n 8.313/1991 é uma forma de estimular o apoio da iniciativa privada ao setor cultural. Nesse sentido, para ter acesso ao recurso disponibilizado o empreendedor cultural deve apresentar uma proposta cultural ao Ministério da Cultura e, caso seja aprovada, é autorizado a captar recursos dos mecanismos legais.

Sendo assim, o Mecenato Federal possui um amplo objetivo: "incentivar as atividades culturais". Esse mecanismo funciona do seguinte modo: a União faculta às pessoas físicas ou jurídicas a opção pela aplicação de parcelas do Imposto sobre a Renda a título de doações ou patrocínios, tanto no apoio direto a projetos culturais apresentados por pessoas físicas ou por pessoas jurídicas de natureza cultural, bem como através de contribuições ao FNC, desde que os projetos atendam aos critérios estabelecidos no PRONAC (CESNIK, 2007; CUNHA FILHO, 2002).

Nesse diapasão, os incentivadores que apoiarem o projeto poderão ter o total ou parte do valor desembolsado deduzido do imposto devido, dentro dos percentuais permitidos pela legislação tributária. Para empresas, até $4 \%$ (quatro por cento) do imposto devido; para pessoas físicas, até $6 \%$ (seis por cento) do imposto de renda devido.

\section{Análise da mudança com a Lei Rouanet}

$\mathrm{Na}$ tabela a seguir, sintetiza-se o processo de mudança da Lei Rouanet e agentes de definição da aplicação dos recursos em cultura: 
Tabela 1 - Análise da mudança com a Lei Rouanet.

\begin{tabular}{|c|c|c|c|c|}
\hline \multicolumn{5}{|c|}{ A dinâmica da Lei Rouanet e dos Agentes Estratégicos } \\
\hline & $\begin{array}{l}\text { CONTEÚDO } \\
\text { (O que mudou) }\end{array}$ & $\begin{array}{l}\text { O PROCESSO } \\
\text { (Como mudou) }\end{array}$ & $\begin{array}{c}\text { O CONTEXTO EXTERNO } \\
\text { (Por que mudou) }\end{array}$ & $\begin{array}{l}\text { O CONTEXTO INTERNO } \\
\text { (Por que mudou) }\end{array}$ \\
\hline Lei Rouanet $\rightarrow$ & $\begin{array}{c}\text { Criação de instrumento de Política } \\
\text { Pública de fomento à cultura criado } \\
\text { pelo Estado brasileiro. }\end{array}$ & $\begin{array}{l}\text { Moroso; Burocrático; Legalista; De } \\
\text { caráter político partidário; De } \\
\text { iniciativa exclusivamente } \\
\text { governamental; Beneficio coletivo. }\end{array}$ & $\begin{array}{l}\text { O reconhecimento e afirmação dos } \\
\text { direitos culturais; Globalização; } \\
\text { Surgimento de blocos econômicos; }\end{array}$ & $\begin{array}{l}\text { Redução da interferência direta do } \\
\text { Estado na produção cultural brasileira; } \\
\text { Redemocratização do Brasil; } \\
\text { Reestruturação administrativa. }\end{array}$ \\
\hline ESTADO $\rightarrow$ & $\begin{array}{l}\text { Detém o poder decisório, o dever } \\
\text { legal. Tomou a iniciativa de } \\
\text { transferir parte da tomada de } \\
\text { decisão para que as organizações e } \\
\text { a sociedade civil decida em quais } \\
\text { projetos devem ser aplicados parte } \\
\text { das verbas nacionais. }\end{array}$ & $\begin{array}{l}\text { Atuou como o único agente de } \\
\text { mudanças, conforme os interesses } \\
\text { dos grupos dominantes, por meio de } \\
\text { um processo moroso, político e } \\
\text { legalista. }\end{array}$ & $\begin{array}{l}\text { Desde a redemocratização do Brasil, é } \\
\text { cada vez mais exigido pela sociedade } \\
\text { em relação tanto à transparência quanto } \\
\text { na qualidade dos destinos de aplicação } \\
\text { dos recursos públicos. Não bastasse isso, } \\
\text { o pais, também, compromete-se com } \\
\text { tratados internacionais econômicos e } \\
\text { socais. }\end{array}$ & $\begin{array}{l}\text { Viveu em intensa transformação de } \\
\text { regime de Estado, de estrutura } \\
\text { administrativa, bem com de sua base } \\
\text { legal constitutiva. }\end{array}$ \\
\hline $\begin{array}{l}\text { EMPREENDEDORES } \\
\text { CULTURAIS } \rightarrow\end{array}$ & $\begin{array}{l}\text { Pela participação representativa, } \\
\text { foram beneficiados com a } \\
\text { possibilidade de levantar o dinheiro } \\
\text { necessário para viabilizar seus } \\
\text { empreendimentos culturais junto à } \\
\text { pessoas físicas e jurídicas.. }\end{array}$ & $\begin{array}{l}\text { Não foram encontrados registros } \\
\text { marcantes do processo de construção } \\
\text { do instrumento de política cultural. } \\
\text { Contudo, buscam usufruir dos } \\
\text { benefícios gerados pela renúncia } \\
\text { fiscal. } \\
\end{array}$ & $\begin{array}{l}\text { Convivem com a enxurrada de mídias } \\
\text { internacionais que promovem o } \\
\text { processo das culturas de massa. }\end{array}$ & $\begin{array}{l}\text { Retomam o exercício de cidadania e } \\
\text { articulação artística abafada por diversas } \\
\text { administrações governamentais. }\end{array}$ \\
\hline ORGANIZAÇÕES $\rightarrow$ & $\begin{array}{l}\text { Pela participação representativa, } \\
\text { foram beneficiados com a } \\
\text { possibilidade de abater parte de seu } \\
\text { imposto de renda na despesa } \\
\text { operacional, em prol de projetos } \\
\text { culturais. }\end{array}$ & $\begin{array}{l}\text { Não foram encontrados registros } \\
\text { marcantes do processo de construção } \\
\text { do instrumento de política cultural. } \\
\text { São os principais agentes de } \\
\text { definição da aplicação dos recursos } \\
\text { em cultura (marketing cultural). }\end{array}$ & $\begin{array}{c}\text { Coexistem com a abertura do mercado } \\
\text { nacional aos conglomerados } \\
\text { internacionais. }\end{array}$ & $\begin{array}{l}\text { Iniciam timidamente, capitaneadas pelas } \\
\text { empresas estatais o movimento de apoio } \\
\text { à atividade cultural. }\end{array}$ \\
\hline$\underset{\rightarrow}{\text { SOCIEDADE CIVIL }}$ & $\begin{array}{l}\text { Pela participação representativa, } \\
\text { foram beneficiados com a } \\
\text { possibilidade de abater parte de seu } \\
\text { imposto de renda em prol de } \\
\text { projetos culturais. }\end{array}$ & $\begin{array}{l}\text { E, infelizmente, possuem pouca } \\
\text { atuação na efetivação dos objetivos } \\
\text { propostos pela Lei Rouanet. A } \\
\text { maioria da população com potencial } \\
\text { de apoiar os empreendimentos } \\
\text { culturais, desconhece a legislação. }\end{array}$ & $\begin{array}{l}\text { Vive intensa transformação cultural, } \\
\text { impulsionada tanto pelos regimes } \\
\text { políticos, quanto pela pujança } \\
\text { tecnológica. }\end{array}$ & $\begin{array}{l}\text { Bastante engajada na redemocratização } \\
\text { brasileira. Contudo, pouco articulada ao } \\
\text { processo de fomento à cultura nacional. }\end{array}$ \\
\hline
\end{tabular}

Fonte: Elaborada pelos autores a partir (2014).

De acordo com a tabela acima, em relação ao Contexto Externo, é possível destacar a grande riqueza de informações contidas no período que envolve a elaboração do instrumento de política pública até o formato hoje adotado (Lei 8.313/80), uma vez considerada produto do projeto de lei apresentado em 1975 ao Senado Nacional. Não se pretende aqui discorrer sobre cada um dos fatos históricos compreendidos nesse período, haja vista que a grandiosidade de cada tema deve ser explorada em espaço maior do que o conferido por este estudo.

Todavia, destaca-se que o reconhecimento dos direitos culturais enquanto direitos humanos fundamentais pelo texto constitucional originário do processo de redemocratização brasileira, bem como a convulsão política e social vivida ao redor do globo somados à intensa evolução tecnológica pressionaram ativamente o processo de mudança da criação da Lei Rouanet. Nessa seara, observa-se que o Estado é cada vez mais exigido pela sociedade em relação tanto à transparência quanto na qualidade dos destinos de aplicação dos recursos públicos, assim como pelos compromissos internacionais assumidos na assinatura de tratados internacionais.
Já os Empreendedores Culturais convivem com a enxurrada de mídias internacionais que promovem o processo de difusão das culturas de massa. Tal movimento é capitaneado pelos Estados Unidos da América que vende ao mundo o "american way of life". Isso se reflete no consumo de todos os tipos de bens culturais, tais como cinema, músicas e espetáculos, por exemplo. Nesse contexto, as Organizações coexistem com a abertura do mercado nacional aos conglomerados internacionais. Tal movimento causou consequências marcantes, em vista do choque de preços, de qualidade e de competitividade dos itens importados em diversos setores da economia brasileira. Enquanto isso, a Sociedade Civil vive intensa transformação cultural, impulsionada tanto pelas mudanças de regimes políticos quanto pela pujança tecnológica.

Já no Contexto Interno, a exemplo do externo, traz consigo uma absoluta riqueza de acontecimento dos quais não se pode dar o merecido detalhamento. Contudo, a síntese instrumental pretende pincelar fatos importantíssimos que corroboraram para a criação de Lei Rouanet. Nesse sentido, cabe realçar o advento do fim do regime militar na administração do Estado brasileiro, a consequente redução da 
interferência direta administrativa na produção cultural brasileira, o processo de redemocratização do Brasil, o reconhecimento da importância da economia criativa e a reestruturação do Ministério da Cultura, todos esses fatores se mostram decisivos na promulgação da lei de incentivo fiscal em prol da produção cultural brasileira.

Diante disso, do Estado ressalta-se a intensa transformação do regime de governo, da estrutura administrativa, bem com da base legal constitutiva.

Nesse contexto interno, narra-se que o Estado liderou a convocação de uma constituinte para definir a nova configuração do Estado Brasileiro, assim como realizou as primeiras eleições diretas após o término do regime militar, organizou plebiscito para definição de regime de Estado, extinguiu e recriou o Ministério da Cultura e, finalmente, promulgou a Lei Rouanet.

Enquanto isso, os Empreendedores Culturais retomam o exercício de cidadania, bem como a articulação artística abafada por diversas administrações governamentais. Além disso, aos poucos vão disseminando as possibilidades desse novo mecanismo de fomento à cultura pelo território brasileiro. Em vista disso, observa-se que os Empreendedores Culturais, timidamente, foram capitaneados pelas empresas estatais no movimento de apoio à atividade cultural.

Ressalta-se, ainda, que não se encontrou registros marcantes do processo de construção do instrumento de política cultural por parte dos Empreendedores Culturais e das Organizações. Todavia, essas encontraram na renúncia fiscal um novo modelo de promoção suas marcas institucionais (marketing cultural). O reflexo disso é a atuação oligopolista de grandes instituições que ditam, por meio de editais de seleção, a linha mestre da produção cultural nacional.

Já a Sociedade Civil se apresenta bastante engajada na redemocratização brasileira. Contudo, pouco articulada ao processo de fomento à cultura nacional, a maioria absoluta da população permanece marginalizada do contexto interno de tomada de decisão sobre as definições da Lei 8.313/91. Com isso, a atuação da Sociedade Civil no Processo de mudança da Lei Rouanet também não aparece nos registros históricos, mesmo sendo importantes agentes de definição da aplicação dos recursos em cultura. Ademais, vê-se que possuem pouca atuação na efetivação dos objetivos propostos pela Lei Rouanet.

Além disso, destaca-se que a maioria da população com potencial de apoiar os empreendimentos culturais, desconhece a legislação e os seus benefícios. Portanto, resta cristalina a grande distância da participação, para não se afirmar a inexistência, dos outros níveis estratégicos que não o Estado na concretização da criação da Lei Rouanet.

Diante disso, é possível observar que o Processo da mudança proposta pelo advento da Lei Rouanet foi moroso e extremamente burocrático, de caráter político partidário e de iniciativa governamental.

Nesse diapasão, demonstram-se os montantes absolutos advindos da renúncia fiscal aplicados no setor cultural brasileiro resultante da aplicação da referida lei, de acordo com os dados disponibilizados pelo MINC (BRASIL, 2014):

Tabela 2 - Média de valores de incentivo de 1993 a 2014.

\begin{tabular}{|c|c|c|c|c|c|c|c|}
\hline \multicolumn{3}{|c|}{ Total de Ince ntivad ores } & \multicolumn{5}{|c|}{ Total do Valor Incentivado } \\
\hline Ano & PESSOAFÍSICA & PESSOA JURÍDICA & Ano & & SSOAFÍSICA & & ESSOA JURÍDICA \\
\hline 1993 & - & 2 & 1993 & $\mathrm{R} \$$ & - & $R \$$ & $21.212,78$ \\
\hline 1994 & 24 & 19 & 1994 & $\mathrm{RS}$ & $4.700,00$ & $\mathrm{R} \$$ & $529.051,57$ \\
\hline 1995 & 181 & 69 & 1995 & $\mathrm{RS}$ & $61.700,77$ & $\mathrm{R} S$ & $12.852 .063,75$ \\
\hline 1996 & 1.438 & 732 & 1996 & $\mathrm{R} S$ & $621.331,01$ & $\mathrm{RS}$ & $111.081 .905,38$ \\
\hline 1997 & 1.790 & 1.123 & 1997 & $\mathrm{R} \$$ & $1.205 .929,22$ & $\mathrm{R} \$$ & $206.743 .378,19$ \\
\hline 1998 & 1.867 & 1.065 & 1998 & $\mathrm{R} S$ & $1.683 .040,72$ & $\mathrm{R} \$$ & $230.890 .328,11$ \\
\hline 1999 & 3.531 & 1.249 & 1999 & $\mathrm{RS}$ & $2.876 .183,92$ & $\mathrm{RS}$ & $208.494 .325,32$ \\
\hline 2000 & 2.998 & 1.334 & 2000 & $\mathrm{R} S$ & $2.124 .645,16$ & $\mathrm{R} \$$ & $287.889 .200,63$ \\
\hline 2001 & 3.215 & 1.173 & 2001 & $\mathrm{R} S$ & $3.799 .979,51$ & $\mathrm{R} \$$ & $364.251 .086,53$ \\
\hline 2002 & 3.322 & 89 & 2002 & $\mathrm{R} \$$ & $2.832 .722,53$ & $\mathrm{R} \$$ & $341.799 .465,73$ \\
\hline 2003 & 2.969 & & 2003 & $\mathrm{R} S$ & $2.538 .147,49$ & $\mathrm{R} \$$ & $428.305 .799,61$ \\
\hline 2004 & 3.596 & 1.778 & 2004 & $\mathrm{RS}$ & $3.912 .280,56$ & $\mathrm{RS}$ & $507.836 .121,43$ \\
\hline 2005 & 3.241 & 2.022 & 2005 & $\mathrm{R} \$$ & $4.191 .101,93$ & $\mathrm{R} \$$ & $721.360 .000,46$ \\
\hline 2006 & 11.874 & 2.311 & 2006 & $\mathrm{R} \$$ & $8.600 .496,53$ & $\mathrm{R} \$$ & $845.522 .372,95$ \\
\hline 2007 & 13.619 & 2.376 & 2007 & $\mathrm{R} \$$ & $8.193 .192,37$ & $\mathrm{R} \$$ & $981.617 .305,45$ \\
\hline 2008 & 12.298 & 2.451 & 2008 & $\mathrm{R} \$$ & $9.317 .267,33$ & $\mathrm{R} \$$ & $951.058 .995,57$ \\
\hline 2009 & 15.499 & 2.384 & 2009 & $\mathrm{RS}$ & $11.779 .786,61$ & $\mathrm{RS}$ & $968.154 .029,20$ \\
\hline 2010 & 19.843 & 2.933 & 2010 & $\mathrm{R} \$$ & $15.853 .713,53$ & $\mathrm{R} \$$ & 1.146. $928.552,19$ \\
\hline 2011 & 15.954 & 3.262 & 2011 & $\mathrm{R} \hat{\mathrm{s}}$ & $18.530 .634,32$ & $\mathrm{R} \$$ & 1. $300.210 .848,95$ \\
\hline 2012 & 16.580 & 3.220 & 2012 & $\mathrm{R} \$$ & $22.298 .049,48$ & $\mathrm{R} \$$ & 1. $254.359 .077,35$ \\
\hline 2013 & 7.901 & 3.457 & 2013 & $\mathrm{R} \$$ & $23.856 .634,69$ & $\mathrm{R} \$$ & 1. $237.486 .476,60$ \\
\hline 2014 & 9.397 & 3.455 & 2014 & $\mathrm{R} S$ & $24.639 .169,20$ & $\mathrm{R} \$$ & $1.299 .623 .894,26$ \\
\hline Total & 151.137 & 39.053 & Total & $\mathrm{RS}$ & $120.424 .902,99$ & & $10.8 \oplus 9.905 .121,17$ \\
\hline
\end{tabular}

Fonte: Elaborada pelos autores a partir de Brasil (2014).

Como se pode observar na tabela acima, destaca-se que o valor atingido na captação junto à uma pessoa física é expressivamente menor do que a jurídica. Talvez, nisso possa residir um dos vários germens da forte tendência de que os incentivadores sejam pessoas jurídicas de grande porte.

Uma vez que o esforço para alcançar o montante necessário somente pelo incentivo de pessoas físicas se torna hercúleo, ao passo que muitas empresas possuem total condições de apoiar vários projetos simultaneamente. Soma-se a isso, o fato de que o apoio financeiro direcionado aos empreendimentos culturais retorna em melhoria e reforço da marca empresarial (CESNIK, 2007; ALVES, 2011; PAULA, 2011). 
Como exemplo disso, destacam-se os seguintes projetos culturais aprovados pelo MINC e largamente, quando não exclusivamente, apoiados pela iniciativa privada. São eles os musicais: Chicago; New York, New York; Cats; As Bruxas de Eastwick; Shrek; Evita e Cabaret, todos apoiados, individualmente, com mais de dois milhões de reais advindos da Lei Rouanet.

Tal prática pode criar distorções com efeitos perversos (Alves, 2011), uma vez que venham flexionam em benefício particular os mecanismos institucionais que regulam a implementação de políticas públicas. A crítica dessa lógica, também entendida como cultura mercadológica, encontra reforço no entendimento de Soares e Silva (2008), no qual os aspectos simbólicos da cultura estão sendo submetidos à lógica do capital na disputa pelo retorno do investimento realizado; e, o valor agregado é a moeda de troca desta relação.

Nesse contexto, dá-se relevo ao fato de que inúmeros projetos culturais que não possuem apelo comercial do porte de musicais internacionais do Cirque du Soleil, Bienal de São Paulo, ou não são executados, propostos e pensados por artistas renomados acabam por não conseguir captar recursos suficientes para tirar suas ideias do papel.

Segundo os dados disponibilizados pelo MinC no sistema SalicNet (BRASIL, 2014), apontam para a triste constatação de que, menos da metade dos projetos aprovados, conseguiram a captação de recursos para a realização do empreendimento cultural.

Entretanto, é possível acreditar que, apesar de não possuírem apelo comercial muitos empreendimentos culturais que não saíram do papel poderiam apresentar um grande interesse social. Sendo assim, uma vez que não conseguem atrair grandes incentivadores, tais projetos necessitariam cativar uma grande soma de pequenos investidores, cidadãos interessados no projeto.

No mais, cabe se ressaltar que, apesar de tímida, a participação da população brasileira no fomento à cultura, em 2014, compôs o montante de $\mathrm{R} \$$ 24.639.169,20. Desse fato, pode-se extrair a visão de que há oportunidade de um aumento da participação popular, desde que os empreendedores culturais não negligenciem as pessoas físicas no processo de captação de recursos.

Reconhece-se, ainda assim, que a prática para a captação de recursos de forma individualizada junto às pessoas físicas possa ser custosa a ponto de inviabilizar a empreitada porta a porta, haja vista que o retorno financeiro médio de incentivo de uma pessoa física é, aproximadamente, 312 vezes inferior ao da pessoa jurídica.

Em vista disso, observa-se que o método tradicional pode ser aprimorado para que se aumente o alcance de captação de recursos fiscais junto às pessoas físicas. Sendo assim, acredita-se que a nova realidade social emergida da Era da Informação requer e, ao mesmo tempo, propõe diferentes formas de democratização e acesso ao capital financiador dos empreendimentos culturais, nos termos que serão a seguir apresentados.

\section{Financiamento Colaborativo - Crowdfunding}

As interações de indivíduos em suas relações familiares, comunitárias, em círculos de amizades, trabalho, estudo, militância, caracterizam as redes sociais informais, que surgem sob as demandas das subjetividades, das necessidades e das identidades. Nessa seara, falar em redes pode significar trabalhar com concepções variadas nas quais parecem se misturar ideias baseadas no senso comum, na experiência cotidiana do mundo globalizado ou ainda em diversas perspectivas teóricas. Além disso, destaca-se que as redes sociais podem ser fomentadas por indivíduos ou grupos com poder de liderança, que articulam pessoas em torno de interesses, necessidades e/ou objetivos comuns. (ACIOLI, 2007; MIZRUCHI, 2006; AGUIAR, 2006).

Contudo, ressalta-se que a introdução da tecnologia não assegura a produtividade, a inovação ou desenvolvimento humano. Para se usufruir do potencial específico da sociedade em rede, mostra-se vital a combinação de iniciativas em setores ligados à tecnologia, aos negócios, à educação, à cultura, à reestruturação espacial, ao desenvolvimento de infraestruturas, à mudança organizacional e à reforma institucional. É na sinergia entre estes processos que as ações têm capacidade de mudar os mecanismos da sociedade em rede. (CASTELLS, M.; CARDOSO, 2005).

Diante das dificuldades de financiamento de projetos culturais com baixo apelo comercial, bem como frente às oportunidades advindas do uso intensivo de tecnologia da informação, mostra-se oportuno uma breve apresentação do conceito de financiamento colaborativo, também, conhecido como Crowdfunding, como metodologia complementar de levantamento de fundos para a viabilização de projetos culturais.

Surgido como parte do conceito crowdsourcing, o termo Crowdfunding foi cunhado pela primeira vez por Jeff Howe, na edição de junho de 2006 da Wired Magazine, no artigo "The Rise of Crowdsourcing". 
De acordo com o referido autor, o Crowdfunding encontra a sua raiz no conceito mais amplo de crowdsourcing (BELLEFLAMME; LAMBERT; SCHWIENBACHER, 2011; HOWE, 2008; KLEEMANN et al., 2008; RUBINTON, 2011).

Nesse sentido, em linhas gerais, o crowdsourcing pode ser entendido como a coleta de contribuições de muitas pessoas para atingir um objetivo (HOWE, 2006). Ou ainda, como o processo em que um grupo progride em direção a uma meta, por meio de solicitações e pequenas contribuições de muitos grupos, em troca de uma forma de remuneração (RUBINTON, 2011).

Colaborando com essa perspectiva, Doan, Ramarkrishnan e Halevy (2011) afirmam que o crowdsourcing se apresenta como um sistema que solicita à multidão de usuários a colaboração para a construção de um artefato duradouro para o benefício de uma comunidade inteira. Assim como Rubinton (2011) que destaca que o advento e a adoção, em massa, da internet aumentaram drasticamente o potencial do crowdsourcing e âmbito de aplicação, no entanto, o conceito preexiste à tecnologia moderna.

Uma vez entendida a dinâmica do crowdsourcing, mostra-se possível avançar no entendimento sobre o Crowdfunding. Desta feita, faz-se oportuno o realce no entendimento de Bradford (2012) em que se destaca outro antecedente do Crowdfunding: o microcrédito. Esse é definido principalmente pelo destinatário do montante: pequenos empreendimentos.

Já o crowdsourcing é definido principalmente pelas contribuições pequenas de um grande número de pessoas para atingir um objetivo comum. Logo o Crowdfunding pode ser entendido como uma simples combinação dessas duas ideias: pequenas contribuições de um grande número de pessoas para pequenos empreendimentos (BRADFORD, 2012).

Dessa forma, destaca-se que o objetivo do Crowdfunding é arrecadar dinheiro a partir de um grande público ("crowd"), em que cada indivíduo irá fornecer uma quantidade muito pequena, ao invés de levantar o dinheiro a partir de um pequeno grupo de investidores sofisticados como bancos, agentes financeiros, investidoresanjo, etc. (HOWE,2006;BELLEFLAMME; LAMBERT e SCHWIENBACHER, 2011).

Além disso, de outro ponto de vista, o risco assumido pelos empreendedores, bem como pelos financiadores (crowdfunders) pode ser menor, não só por causa das pequenas quantidades que fornecem individualmente, mas pelo fato de que a multidão que financia pode ainda se tornar consumidores. Tal divulgação, certamente, exigiria campanha publicitária significativa se o empreendimento fosse financiado pelos meios tradicionais (SCHWIENBACHER; LARRALDE, 2010).

Para tanto, o Crowdfunding se utiliza do convite, principalmente através da Internet, para o levante de recursos financeiros seja em forma de doação, troca do produto futuro ou alguma forma de recompensa que pode ser monetária. Com isso, os empreendedores podem postar o seu projeto na plataforma e beneficiar de visibilidade da plataforma para chegar a potenciais investidores. (BELLEFLAMME; LAMBERT; SCHWIENBACHER, 2011).

Observa-se, contudo, que Crowdfunding se mostra mais difícil de implementar do que o crowdsourcing, haja vista as diversas complexidades legais, técnicas e sociais que se pode imaginar decorrente de uma plataforma online de projeto de financiamento (RUBINTON, 2011). Dentre as quais, pode-se destacar, em especial, a regulação do fluxo financeiro e sua respectiva tributação. Entretanto, de acordo com Crowdsourcing. org (2013), até o final do ano de 2013, mais de 450 plataformas de Crowdfunding movimentaram quase US\$ 5,1 bilhão e financiaram com êxito mais de um milhão de projetos. No Brasil, há pelo menos 30 plataformas de financiamento colaborativo que as contemplam desde projetos artísticos à tecnológicos. Com isso, restou demonstrado que o financiamento colaborativo tem o condão de viabilizar a execução de projetos que possuem diversos níveis de interesse comercial e/ou social, avaliados por seu público alvo que voluntariamente financia, e, por vezes, beneficiase diretamente com o resultado do projeto apoiado. Além disso, restou demonstrado que o financiamento colaborativo tem o condão de viabilizar a execução de projetos que possuem diversos níveis de interesse comercial e/ou social, avaliados por seu público alvo que voluntariamente financia, e, por vezes, beneficiase diretamente com o resultado do projeto apoiado.

\section{Análise da mudança}

Antes do advento do Crowdfunding os empreendedores culturais seguiam o caminho tradicional para transformar suaideia em realidade, tais como apresentar planos de negócios aos agentes financiadores, como bancos e produtoras, ou até mesmo recorriam aos editais de grandes organizações de fomento à cultura. $\mathrm{Na}$ tabela a seguir, sintetiza-se o processo de mudança do Crowdfunding. 
Tabela 3 - Análise do Crowdfunding

SITUAÇ̃̃O ANTERIOR: Empreendedores culturais buscam os meios tradicionais de financiamento - grandes montantes de poucas instituições (Bancos, Produtoras, Editais).

\begin{tabular}{|c|c|c|c|c|}
\hline \multicolumn{5}{|c|}{ A dinâmica do Crowdfunding e dos Agentes Estratégicos } \\
\hline & $\begin{array}{l}\text { CONTEÚDO } \\
\text { (O que mudou) }\end{array}$ & $\begin{array}{l}\text { O PROCESSO } \\
\text { (Como mudou) }\end{array}$ & $\begin{array}{c}\text { O CONTEXTO EXTERNO } \\
\text { (Por que mudou) }\end{array}$ & $\begin{array}{c}\text { O CONTEXTO INTERNO } \\
\text { (Por que mudou) }\end{array}$ \\
\hline Crowdfunding $\rightarrow$ & $\begin{array}{l}\text { Método alternativo de se financiar } \\
\text { empreendimentos culturais } \\
\text { idealizados por empreendedores }\end{array}$ & $\begin{array}{c}\text { Transformação estrutural } \\
\text { multidimensional; Emergência de } \\
\text { um novo paradigma tecnológico; } \\
\text { Formação das macroestruturas } \\
\text { socioculturais digitais, composta } \\
\text { milhões de pessoas. }\end{array}$ & $\begin{array}{l}\text { Meio de aliviar as restrições para o } \\
\text { financiamento de indivíduos; } \\
\text { proporcionada pela revolução } \\
\text { tecnológica; Acesso e validação das } \\
\text { informações do projeto fomentado, bem } \\
\text { como do responsável executivo; } \\
\text { Legitimação do novo método. }\end{array}$ & $\begin{array}{c}\text { Alta Velocidade das informações; } \\
\text { Dinâmica é simples; De fácil execução; } \\
\text { Com linguagem acessível; Disponivel a } \\
\text { quem possuir acesso à internet; Iniciativa } \\
\text { privada; Beneficio coletivo }\end{array}$ \\
\hline ESTADO $\rightarrow$ & $\begin{array}{c}\text { Detém o poder regulatório. Porém, } \\
\text { ainda não se manifestou em relação } \\
\text { ao novo modelo utilizado. Destaca- } \\
\text { se que possui regulamentações } \\
\text { esparsas e dessincronizadas com o } \\
\text { surgimento da nova dinâmica de } \\
\text { financiamento. } \\
\end{array}$ & $\begin{array}{l}\text { Tem se mantido à margem da } \\
\text { implementação dessa nova } \\
\text { metodologia de financiamento de } \\
\text { empreendimentos culturais. }\end{array}$ & $\begin{array}{c}\text { Há um movimento no sentido de propiciar } \\
\text { a população o acesso às novas tecnologias } \\
\text { de bens e serviços de telecomunicações e } \\
\text { eletrônicos. }\end{array}$ & $\begin{array}{l}\text { Mostrou-se inerte ao surgimento de } \\
\text { plataformas de financiamento colaborativo } \\
\text { no território nacional. }\end{array}$ \\
\hline $\begin{array}{l}\text { EMPREENDEDORES } \\
\text { CULTURAIS } \rightarrow\end{array}$ & $\begin{array}{l}\text { Tomaram a inciativa na elaboração } \\
\text { de uma nova forma de viabilizar } \\
\text { empreendimentos culturais. }\end{array}$ & $\begin{array}{c}\text { Buscam, de forma crescente, } \\
\text { participar ou lançar as próprias } \\
\text { plataformas de captação de } \\
\text { recursos. }\end{array}$ & $\begin{array}{l}\text { Conectam-se com o mundo revolucionado } \\
\text { pela nova configuração de fluxo de } \\
\text { informações desterritorializadas, em } \\
\text { tempo real ou sob demanda. Trocam } \\
\text { informações e conhecimentos de forma } \\
\text { inédita, até então, bem como ajudam a } \\
\text { construir uma nova realidade. }\end{array}$ & $\begin{array}{l}\text { Seguiram os passos de outros setores que já } \\
\text { se beneficiavam com o financiamento } \\
\text { colaborativo, como é caso do } \\
\text { desenvolvimento de inovações } \\
\text { tecnológicas. }\end{array}$ \\
\hline ORGANIZAÇÕES $\rightarrow$ & $\begin{array}{l}\text { Estão aderindo e se beneficiando } \\
\text { gradativamente da nova forma } \\
\text { idealizada pelos empreendedores. }\end{array}$ & $\begin{array}{l}\text { Demonstram pouca movimentação } \\
\text { para a utilização dessa nova } \\
\text { dinâmica de financiamento à } \\
\text { projetos, no território nacional. }\end{array}$ & $\begin{array}{l}\text { Migram gradualmente para o espaço } \\
\text { virtual, no intuito de aumentar o } \\
\text { relacionamento com todos os seus } \\
\text { stakeholders. }\end{array}$ & $\begin{array}{l}\text { Em sua maioria, não fomentaram } \\
\text { diretamente o movimento de criação e } \\
\text { participação de plataformas de } \\
\text { financiamento à cultura. }\end{array}$ \\
\hline$\underset{\rightarrow}{\text { SOCIEDADE CIVIL }}$ & $\begin{array}{l}\text { Estão aderindo e se beneficiando } \\
\text { gradativamente da nova forma } \\
\text { idealizada pelos empreendedores. }\end{array}$ & $\begin{array}{c}\text { Ainda que não atinja a maior } \\
\text { parcela da população, é o grande } \\
\text { agente de divulgação e promoção } \\
\text { dessa nova modalidade de } \\
\text { incentivo. } \\
\end{array}$ & $\begin{array}{c}\text { Absorveu e foi absorvida por essa nova } \\
\text { realidade. Os impactos nas relações } \\
\text { sociais, familiares e institucionais estão } \\
\text { em um novo e irreversível processo de } \\
\text { mudança. }\end{array}$ & $\begin{array}{l}\text { A sociedade civil é a grande responsável } \\
\text { pela a validação e financiamento dos } \\
\text { empreendedorismo. }\end{array}$ \\
\hline
\end{tabular}

Fonte: Elaborada pelos autores (2014).

O que chama a atenção é a inércia do Estado que, mesmo possuindo o poder regulatório, não possui nenhuma proposta em andamento para regularizar a dinâmica do financiamento colaborativo que anda a passos largos no contexto nacional e internacional. Até o presente momento, o que se encontra são regulamentações esparsas, ao longo do arcabouço jurídico, dessincronizadas com a dinâmica proposta pelo financiamento colaborativo.

Já em relação aos Empreendedores Culturais, cabe o destaque pela inciativa na elaboração de uma nova forma de viabilizar empreendimentos culturais. O novo desafio é fruto do bem sucedido modelo internacional que alcança diversos setores além do cultural. De toda a forma, a dimensão continental do território brasileiro não parece intimidar, mas sim incentivar os empreendedores de todo o canto do Brasil a divulgarem seus projetos em plataformas de apoio financeiro coletivo.

Não tão inerte quanto o Estado, as Organizações se apresentam aderindo e se beneficiando gradativamente da nova forma idealizada pelos empreendedores. Contudo, ainda se percebe um pequeno apoio institucional, liderado pelas empresas de comunicação que começam a chamar a atenção para a existência do financiamento coletivo como forma de fomento à produção cultural.

Em relação a isso, a sociedade civil tal como as Organizações tem aumentado a sua participação tanto no apoio quanto na divulgação do Crowdfunding. Ainda que não tenha se investido dessa forma, acredita-se que a sua participação é fundamental não só no apoio financeiro de projetos, mas, sobretudo na formulação e formatação do conteúdo das plataformas de financiamento colaborativo, principalmente em virtude da "sabedoria das multidões".

Por conseguinte, passa-se agora à apreciação do Contexto Externo da mudança do Método contemporâneo. Nesse sentido, entendendo-se que o movimento relativo ao Crowdfunding ganha reconhecimento internacional a partir de 2006, é possível observar que o Contexto Externo à realidade brasileira ganha contornos a partir de transformação estrutural multidimensional da sociedade em virtude da revolução tecnológica vivida nas últimas décadas.

Diante desse contexto, os Empreendedores Culturais se conectam com o mundo revolucionado pela nova configuração de fluxo de informações desterritorializadas, em tempo real ou sob demanda. Trocam informações e conhecimentos de forma 
inédita, até então, bem como ajudam a construir uma nova realidade. O aumento do volume do conteúdo veiculado pela sociedade em rede é sobremaneira superior ao vivido em épocas anteriores. Por conta disso, o intercambio, bem com a realização de projetos com equipes de agentes culturais espalhados pelo globo se intensificou propiciando o ambiente ideal para o surgimento e consolidação das redes de financiamento coletivos internacionais.

Já as Organizações migram gradualmente para o espaço virtual, no intuito de aumentar o relacionamento com todos os seus stakeholders. Dessa forma, expõemse para todos os tipos de respostas que o ambiente externo pode oferecer.

Da mesma forma, a Sociedade Civil absorveu e foi absorvida por essa nova realidade. Os impactos nas relações sociais, familiares e institucionais estão em um novo e irreversível processo de mudança. Exemplo disso é a formação das macroestruturas socioculturais digitais (redes sociais), composta por milhares ou mesmo milhões de pessoas.

O Contexto Interno da mudança gerada pelo Crowdfunding no Brasil pauta seus motivos principalmente no encontro de uma metodologia, capaz de aliviar as restrições para o financiamento de indivíduos que acreditam no potencial de suas ideais. Isso só foi possível graças à experiência internacional que demonstrou ser possível aclimatação com a nova realidade proporcionada pela revolução tecnológica, e tornou viável tanto ao credor quanto ao investidor ter acesso e validar as informações do projeto fomentado, bem como do responsável executivo.

Mais uma vez, observa-se que o Estado se mostra inerte ao surgimento de plataformas de financiamento colaborativo no território nacional, e mesmo tendo criado a Secretaria da Economia Criativa (SEC), não moveu esforços nos sentido de normatizar essa nova dinâmica financeira.

Entretanto, é possível se afirmar, estritamente no tangente aos empreendimentos culturais, que a própria Lei Rouanet é capaz de subsidiar a regulação do Crowdfunding de projetos culturais. Isso porque, a referida lei possibilita aportes pequenos ou milionários por parte das pessoas jurídicas e pessoas físicas.

Caso houvesse a participação massiva da população brasileira, a utilização da Lei Rouanet se aproximaria sobremaneira da realidade do financiamento do Crowdfunding. A diferença residiria na utilização do imposto de renda como origem das pequenas contribuições individuais.
Já os Empreendedores Culturais, no Contexto Interno, lideraram as atividades seguindo os passos de outros setores que já se beneficiavam com o financiamento colaborativo, como é caso do desenvolvimento de inovações tecnológicas. A estrutura foi copiada das plataformas internacionais, principalmente da kickstarter.com, a mais antiga e bem-sucedida.

No mais, ressalta-se que a sociedade civil é a grande responsável pela validação da ideia do Crowdfunding, uma vez que a existência das plataformas de financiamento colaborativo depende diretamente do nível de participação dos indivíduos.

Em relação ao processo de mudança operado pelo Crowdfunding é possível se afirmar que seu surgimento segue a alta velocidade de troca de informações proporcionadas pelas novas tecnologias. Por meio de uma dinâmica simples, de fácil execução, com linguagem acessível, disponível a quem possuir acesso à internet, é possível seguir a filosofia "faça você mesmo". Diante disso, novamente, observa-se que o Estado tem se mantido alheio à implementação dessa nova metodologia de financiamento de empreendimentos culturais. Em contrapartida, os empreendedores Culturais buscam, de forma crescente, participar ou lançar as próprias plataformas de captação de recursos.

\section{Resumo comparativo}

Por todo o exposto, é possível perceber que o Processo de Mudança da criação da Lei Rouanet e do surgimento do Crowdfunding de projetos culturais no Brasil são díspares em Conteúdo, Contexto e Processo. Contudo, acredita-se que a força motriz de ambos os métodos é idêntica, sendo ela a promoção da produção de empreendimentos culturais nacionais, conforme se vê na tabela a seguir. 
Tabela 4 - Análise do Lei Rouanet x Crowdfunding

\begin{tabular}{|c|c|c|}
\hline & LEI ROUANET & CROWDFUNDING \\
\hline CONTEÚDO & $\begin{array}{l}\text { - Instrumento de Política Pública de } \\
\text { fomento à cultura criado pelo } \\
\text { Estado brasileiro. }\end{array}$ & $\begin{array}{l}\text { - Método alternativo de se financiar } \\
\text { empreendimentos culturais } \\
\text { idealizados por empreendedores }\end{array}$ \\
\hline $\begin{array}{c}\text { CONTEXTO } \\
\text { EXTERNO }\end{array}$ & $\begin{array}{l}\text { - O reconhecimento e afirmação dos } \\
\text { direitos culturais. } \\
\text { - } \quad \text { Globalização } \\
\text { - } \\
\text { Invençãono do computador pessoal, } \\
\text { do computador pessoal, da } \\
\text { internet, dos telefones celulares, } \\
\text { da banda larga, tablets. }\end{array}$ & $\begin{array}{l}\text { - } \begin{array}{l}\text { Transformação } \\
\text { multidimensional }\end{array} \\
\text { - Emergência de um novo paradigma } \\
\text { tecnológico } \\
\text { - } \\
\text { - } \text { As novas formas de comunicação } \\
\text { Formação das macroestruturas } \\
\text { socioculturais digitais, composta } \\
\text { por milhares ou mesmo milhões de } \\
\text { pessoas. }\end{array}$ \\
\hline $\begin{array}{c}\text { CONTEXTO } \\
\text { INTERNO }\end{array}$ & $\begin{array}{l}\text { - Redução da interferência direta do } \\
\text { Estado na produção cultural } \\
\text { brasileira } \\
\text { - Redemocratização do Brasil } \\
\text { - Reconhecimento da importância } \\
\text { da economia criativa } \\
\text { - Reestruturação administrativa }\end{array}$ & $\begin{array}{l}\text { - Meio de aliviar as restrições para o } \\
\text { financiamento de indivíduos } \\
\text { - A aclimatação com a nova realidade } \\
\text { proporcionada pela revolução } \\
\text { tecnológica } \\
\text { - Acesso e validação das informações } \\
\text { do projeto fomentado, bem como do } \\
\text { responsável executivo. } \\
\text { - Legitimação do novo método. }\end{array}$ \\
\hline PROCESSO & $\begin{array}{l}\text { - } \text { Moroso (16 anos); } \\
\text { - } \text { Burocrático; } \\
\text { - } \text { Degalista } \\
\text { - } \quad \text { De caráter político partidário; } \\
\text { governamentiva exclusivamente } \\
\text { - Beneficio coletivo }\end{array}$ & $\begin{array}{l}\text { - Velocidade frenética } \\
\text { - Dinâmica é simples, } \\
\text { - De fácil execução, } \\
\text { - } \quad \text { Com linguagem acessível, } \\
\text { - Disponível a quem possuir acesso à } \\
\text { internet. } \\
\text { - Iniciativa privada } \\
\text { - Beneficio coletivo }\end{array}$ \\
\hline
\end{tabular}

Fonte: Elaborada pelos autores a partir de Brasil (2014).

Diante disso, entende-se que ambos os métodos possuem o potencial de reforço mútuo, no sentido de criação de plataformas virtuais capazes de abrigar os diversos tipos de empreendimentos culturais. 


\section{Proposta de modelo alternativo de plataforma cultural}

Ao se observar quadro após quadro de análise comparativa, é possível notar que o Processo de Mudança da criação da Lei Rouanet e do surgimento do Crowdfunding de projetos culturais no Brasil são díspares em Conteúdo, Contexto e Processo. Contudo, acredita-se que a força motriz de ambos os métodos é idêntica, sendo ela a promoção da produção de empreendimentos culturais nacionais.

No intuito de alcançaros respectivos objetivos, os níveis estratégicos caracterizados pelos Empreendedores Culturais e pelo Estado oscilam na ênfase de participação, sendo mínima dos primeiros quando se trata da criação de conteúdo do instrumento de política Pública da Lei Rouanet e máxima na implementação do Crowdfunding.

Ao passo que Organizações e a Sociedade civil se mostram, em geral, pouco participativas na criação de conteúdos, mas influentes nos processos, principalmente, na manipulação da Lei Rouanet, por parte das Organizações e na validação e acreditação do Crowdfunding, no caso da Sociedade Civil.

Diante dessas e outras informações apresentadas ao longo do estudo, buscou-se modelar uma organização virtual de Crowdfunding capaz de fomentar a intensa interação dos níveis estratégicos em prol da melhoria na captação de recursos financiadores de projetos culturais viabilizados pela Lei Rouanet.

Nesse sentido, a Organização Virtual Permanente de Empreendimentos Culturais apresenta os seguintes elementos estruturantes: Empreendedores Culturais, Estado (Administração Federal), Organizações (pessoas jurídicas), Sociedade (pessoas físicas) e o Gestor Virtual.

Os mesmos possuem por sua vez, as seguintes competências:

A. Empreendedores Culturais: conceber, propor, divulgar, executar, prestar contas de empreendimentos culturais;

B. Estado: normatizar, certificar, fiscalizar e aprovar todas as etapas dos empreendimentos que se utilizam de recursos públicos.

C. Organizações e Sociedade: avaliar, divulgar, financiar, fiscalizar e usufruir dos bens culturais produzidos.

D. Gestor Virtual: criar e manter a plataforma virtual, promover os empreendimentos que se utilizem das competências complementares, como s se demonstra na figura a seguir:

Figura 2 - Plataforma Virtual Lei Rouanet + Crowdfunding.

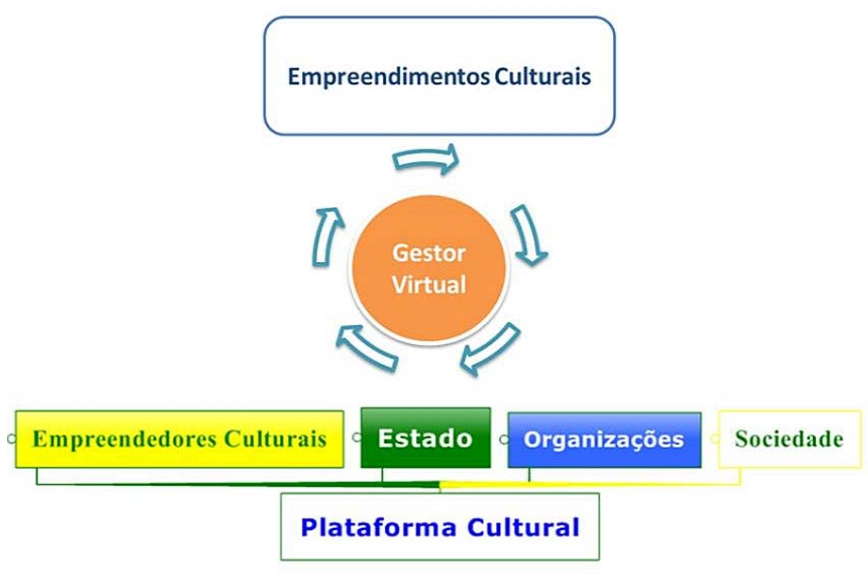

Fonte: Elaborada pelos autores a partir de Brasil (2014).

Acredita-se que a Plataforma Cultural deve beneficiar os seus participantes de forma ampla, bem como motivá-los a interagir, haja vista as seguintes possibilidades expostas na tabela 5 . 
Tabela 5 - Tabela de benefícios

\begin{tabular}{|c|c|}
\hline Benefícios comparados aos métodos anteriores & Deficiência dos métodos anteriores \\
\hline $\begin{array}{l}\text { 1. Dispor de uma estrutura de apoio à elaboração de projetos } \\
\text { para aprovação do Minc, uma vez dispostos o conteúdo de diversos } \\
\text { projetos aprovados pelo MINC; }\end{array}$ & $\begin{array}{l}\text { Falta de apoio à estruturação de projetos } \\
\text { culturais. }\end{array}$ \\
\hline $\begin{array}{l}2 . \quad \text { Acessar calendário de editais de captação direta e de empresas } \\
\text { interessadas em apoiar projetos culturas com recursos originados leis } \\
\text { de incentivo fiscais, bem como informar novos editais e organizações } \\
\text { não presentes no calendário; }\end{array}$ & $\begin{array}{l}\text { Ausência de informações sobre abertura e } \\
\text { encerramento de novos editais. }\end{array}$ \\
\hline $\begin{array}{l}\text { 3. Utilizar de acesso direto a todos os potenciais incentivadores } \\
\text { do território nacional; }\end{array}$ & $\begin{array}{l}\text { Barreiras geográficas somadas a falta de } \\
\text { informação. }\end{array}$ \\
\hline $\begin{array}{l}\text { 4. } \quad \text { Criar rede de fornecedores de serviços/produtos e preços } \\
\text { necessários para a execução dos projetos idealizados; }\end{array}$ & $\begin{array}{l}\text { Ausência de redes de relacionamento } \\
\text { focada na cadeia produtiva da cultura. }\end{array}$ \\
\hline $\begin{array}{l}\text { 5. Utilizar estrutura de captação de recursos de Crowdfunding } \\
\text { legalmente amparado na Lei Rouanet; }\end{array}$ & $\begin{array}{l}\text { Sem a exigência de remunerar a plataforma } \\
\text { como captador de recursos. }\end{array}$ \\
\hline 6. Utilizar sistema online de Prestação de Contas; & Ausente em todos os métodos. \\
\hline $\begin{array}{l}\text { 7. Profissionalizar o processo de execução de empreendimentos } \\
\text { culturais. }\end{array}$ & $\begin{array}{l}\text { Falta de conexão dos profissionais da cadeia } \\
\text { produtiva. }\end{array}$ \\
\hline 8. $\quad$ Promover amplamente o instrumento de política pública; & $\begin{array}{l}\text { Restrito aos familiarizados com a Lei } \\
\text { Rouanet. }\end{array}$ \\
\hline $\begin{array}{l}\text { 9. Ganhar de ferramentas tecnológicas de monitoramento da } \\
\text { produção cultural nacional capaz de alimentar o Sistema Nacional de } \\
\text { Informações e Indicadores Culturais (SNIIC) aumentando a } \\
\text { transparência na gestão dos gastos públicos }\end{array}$ & $\begin{array}{l}\text { Não há conexão entre as plataformas e o } \\
\text { MINC. }\end{array}$ \\
\hline 10. Fomentar a cadeia produtiva da Economia Criativa & Resultados insatisfatórios. \\
\hline $\begin{array}{l}\text { 11. Facilitar, a todos, os meios para o livre acesso às fontes da } \\
\text { cultura e o pleno exercício dos direitos culturais; }\end{array}$ & $\begin{array}{l}\text { Em maioria estão restritos aos } \\
\text { empreendimentos de alto apelo comercial. }\end{array}$ \\
\hline $\begin{array}{l}\text { 12. Promover e estimular a regionalização da produção cultural e } \\
\text { artística brasileira, com valorização de recursos humanos e conteúdos } \\
\text { locais; }\end{array}$ & $\begin{array}{l}\text { Os recursos se concentram no sudeste } \\
\text { brasileiro. }\end{array}$ \\
\hline $\begin{array}{l}\text { 13. Apoiar, valorizar e difundir o conjunto das manifestações } \\
\text { culturais e seus respectivos criadores; }\end{array}$ & $\begin{array}{l}\text { Em maioria estão restritos aos } \\
\text { empreendimentos de grandes instituições; }\end{array}$ \\
\hline $\begin{array}{l}\text { 14. Salvaguardar a sobrevivência e o florescimento dos modos de } \\
\text { criar, fazer e viver da sociedade brasileira; }\end{array}$ & $\begin{array}{l}\text { Há grande distribuição de recursos para } \\
\text { produções internacionais. }\end{array}$ \\
\hline $\begin{array}{l}\text { 15. Estimular a produção e difusão de bens culturais de valor } \\
\text { universal, formadores e informadores de conhecimento, cultura e } \\
\text { memória; }\end{array}$ & $\begin{array}{l}\text { Há um foco muito grande a produção de } \\
\text { eventos. }\end{array}$ \\
\hline 16. Priorizar o produto cultural originário do País; & Idem 14 \\
\hline $\begin{array}{l}\text { 17. Informação sobre novos empreendimentos culturais do } \\
\text { interesse do investidor. }\end{array}$ & Idem 13 \\
\hline $\begin{array}{l}\text { 18. Verificação do número do de cadastro dos projetos nos órgãos } \\
\text { oficiais; }\end{array}$ & Idem 9 \\
\hline 19. Viabilização de contato direto ao produtor cultural; & Idem 4 \\
\hline Cálculo do poder de apoio por meio da dedução; & Não há instrumentos disponíveis. \\
\hline 21. Transferências de doação de recursos; & Pouca trar \\
\hline $\begin{array}{l}\text { 22. Emissão de recibo de doação, bem como de email com os } \\
\text { dados necessários próximo da data de regularização junto ao fisco; }\end{array}$ & Idem 20 \\
\hline $\begin{array}{l}\text { 23. Acompanhamento e indicadores de execução, captação e } \\
\text { prestação contas do projeto incentivado; }\end{array}$ & Idem 21 \\
\hline $\begin{array}{l}\text { 24. Criação de ranking alimentado pelos usuários de qualidade de } \\
\text { projetos, produtores, fornecedores, patrocinadores; }\end{array}$ & Idem 20 \\
\hline
\end{tabular}

25. Disponibilização de uma nova forma de gerir parte dos recursos públicos capaz de promover a cidadania, educação e emancipação Social.

Fonte: Elaborada pelos autores a partir de Brasil (2014). 
É cediço que o funcionamento da plataforma dependerá da utilização de um arsenal de instrumentos tecnológicos existentes, bem como necessários de desenvolvimento. Além disso, vislumbra-se a necessidade de o projeto, em seu estágio inicial ser fomentado pelas empresas, autarquias e órgãos estatais, tais como a Lei Rouanet o foi em seus primeiros anos de existência.

\section{Considerações finais}

Diante do esposado, é possível afirmar que a Lei Rouanet é um importante instrumento de democratização da tomada de decisão da aplicação dos recursos destinados ao fomento da cadeia produtiva dos empreendimentos culturais que traz, ao longo de duas décadas de existência, diversos fatores de sucesso e insucesso.

Dentre os objetivos bem sucedidos, pode-se destacar que a Lei 8.313/91 conseguiu, até então: fomentar o exercício dos direitos culturais em território nacional; firmar política pública de Estado em prol dos empreendimentos culturais; aportar mais de 10 bilhões de reais na cadeia produtiva da economia criativa.

Contudo, observou-se que o instrumento legal continua a falhar em diversos aspectos, dos quais se destaca a perpetuação do monopólio das grandes cooperações na definição do produto cultural a ser desenvolvido; a concentração de recursos aplicados no Sudeste; a restrição, na maioria dos casos analisados, da produção de obras de artistas de alto renome ou grande apelo comercial; a vultosa arrecadação destinada à produção de espetáculos internacionais que não possuem origem na cultura brasileira; a carência de metodologia de captação de recursos que democratizem o acesso e a decisão da aplicação do erário público; e, principalmente a ausência de sensibilização da sociedade civil uma vez que a maioria absoluta da população brasileira que paga o imposto sobre a renda desconhece a existência da lei, bem como seus benefícios o que se reflete na baixa participação social desse instrumento de política púbica.

Nesse universo, percebe-se que o Crowdfunding aparece como alternativa para a democratização do acesso ao capital financiador dos empreendimentos culturais. Nesse contexto, percebeu-se que o Brasil apresenta uma positiva posição no âmbito mundial de Crowdfunding, tanto pelo número de plataforma quanto pelo valor já captados por algumas dessas, acima de quatro milhões em menos de dois anos.

Ao longo da apresentação do modelo complementar de plataforma cultural, demonstrou-se que a sua utilização pode, de forma ímpar, impulsionar a interação dos níveis estratégicos (Empreendedores Culturais, Estado, Organizações e Sociedade), assim como fomentar a emancipação da sociedade civil tanto na definição dos destinos dos recursos públicos quanto da efetivação das políticas culturais brasileiras quanto no processo decisório da aplicação do erário em outras áreas abrangidas por leis de incentivo fiscal.

Ademais, entende-se que a lógica atinente à concepção, captação de recursos de renúncia fiscal e realização dos projetos culturais em comento pode e deve ser estendida a outras áreas de interesse público.

Nesse sentido, mostra-se oportuna a criação de legislações específicas de renúncia fiscal e organizações virtuais de Crowdfunding capazes de gerir as etapas de recebimento de propostas de projetos, captação de recursos, execução e prestação de contas nas áreas de educação, saúde, infraestrutura e segurança, tal como ocorre hoje na esfera do empreendimento cultural.

Nisso, acredita-se residir o gérmen de uma nova aliança entre a sociedade civil e o Estado, com foco na dinamização do compromisso comunitário de construção do bem estar social, por meio de aparatos legais e tecnológicos capazes de viabilizar a gestão conjunta da aplicação dos recursos advindos da receita tributária nacional.

Por fim, acredita-se que o engajamento dos cidadãos no processo de formulação de políticas públicas, por meio da plataforma de gestão de recursos públicos proposta, resultará na obtenção de uma nova gramática societária capaz de fortalecer as relações governo-cidadão, ampliar o exercício da democracia e fomentar a emancipação social.

\section{Referências}

ACIOLI, S. Redes sociais e teoria social: revendo os fundamentos do conceito. Inf. Londrina, v. 12, n. esp. 2007.

\section{AMBONI, N. O Caso Cecrisa S.A.: uma}

aprendizagem que deu certo. Tese (Doutorado em Engenharia de Produção e Sistemas) - Universidade Federal de Santa Catarina, Florianópolis, 1997.

AGUIAR, S. Redes sociais e tecnologias digitais de informação e comunicação. Rio de Janeiro: 
NUPEF-RITS, 2006. Disponível em: $<\underline{\text { http:// }}$ www.nupef.org.br/sites/default/files/rel nupef redes 2006.pdf>. Acesso em: 23 mai. 2015.

AGRAWAL, A.; CATALINI, C.; GOLDFARB, A. The Geography of Crowdfunding, 2011. Disponível em: < http://www.nber.org/papers/ w16820.pdf?new window=1>. Acesso em: 23 mai. 2015.

ALMEIDA, C. J. M. A Arte é Capital. Rio de Janeiro: Rocco, 1993. p. 25-26.

ALVES, M. A. Articulação entre cultura e mercado: a descentralização das políticas culturais. XXVIII Congresso Internacional da Associação Latino-Americana de Sociologia (ALAS). Universidade Federal de Pernambuco, 2011.

AZEVEDO, F. A cultura brasileira. 5. ed. São Paulo: USP, 1971.

BELLEFLAMME, P.; LAMBERT, T.; SCHWIENBACHER, A. Crowdfunding: Tapping the Right Crowd. Social Science Research Network, Core discussion paper, 2011/32, 2011. Disponível em: $<$ http://papers.ssrn.com/sol3/papers.cfm?abstract $\underline{\mathrm{id}=1578175}>$. Acesso em: 23 mai. 2015.

BRASIL. Constituição (1988). Constituição da República Federativa do Brasil. Brasilia, DF: Senado Federal, 1998.

. Lei $\mathrm{n}^{\mathrm{0}} \mathbf{7 . 5 0 5}$, de 2 de julho de 1986. Dispõe sobre benefícios fiscais na área do imposto de renda concedidos a operações de caráter cultural ou artístico. Presidência da República, Subchefia para Assuntos Jurídicos. Brasília, 1986. Disponível em: $<\underline{\text { http://www. }}$ planalto.gov.br/ccivil 03/leis/L7505.htm $>$. Acesso em: 23 mai. 2015.

Lei $\mathrm{n}^{\circ} 8.313$, de 23 de dezembro de 1991. Restabelece princípios da Lei $n^{\circ} 7.505$, de 2 de julho de 1986, institui o Programa Nacional de Apoio à Cultura (Pronac) e dá outras providências. Presidência da República, Casa Civil, Subchefia para Assuntos Jurídicos. Brasília, 1991. Disponível em: < $\underline{\text { http://www. }}$ planalto.gov.br/ccivil 03/leis/L8313cons.htm>.

Acesso em: 23 mai. 2015.

. MINISTÉRIO DA CULTURA, Funarte.

Cultura em números: anuário de estatísticas culturais, 2009. 2. ed. Brasília: Minc, 2009. Disponível em: < http://www2.cultura.gov.br/site/wp-content/ uploads/2009/10/cultura em numeros 2009 final. pdf>. Acesso em: 23 mai. 2015.
. MINISTÉRIO DA CULTURA, SalicNet.

Brasília, 2014. Disponível em: $<$ http://sistemas. cultura.gov.br/salicnet/Salicnet/Salicnet.php>. Acesso em: 23 mai. 2015.

BRADFORD, C. S. Crowdfunding and the Federal Securities Laws. Social Science Research Network, Columbia Business Law Review, v. 2012, n. 1, 2012. Disponível em: $<\underline{\text { http://papers.ssrn.com/sol3/papers. }}$ cfm?abstract $\mathrm{id}=1916184>$. Acesso em: 23 mai. 2015.

CASTELLS, M.; CARDOSO, G. (Orgs.). A Sociedade em Rede: do Conhecimento à Acção Política. Debates - Presidência da República: Portugal, 2005. Disponível em: < http://www.cies.iscte.pt/ destaques/documents/Sociedade em Rede CC.pdf $>$. Acesso em: 23 mai. 2015.

CARVALHO, C. A. P. O estado e a participação conquistada no campo das políticas públicas para a cultura no Brasil. In: CALABRE, L.

(Org.). Políticas culturais: reflexões e ações. São Paulo: Itaú Cultural; Rio de Janeiro: Fundação Casa de Rui Barbosa, 2009. Disponível em: < $\underline{\text { http:// }}$ d3nv1jy4u7zmsc.cloudfront.net/wp-content/ uploads/itau pdf/001513.pdf > . Acesso em: 23 mai. 2015.

CESNIK, F. S. Guia do incentivo à cultura. 2. ed. Barueri: Manole, 2007.

COELHO, T. Dicionário crítico de política cultural: cultura e imaginário. São Paulo: Fapesp: Iluminuras, 1997.

. O novo papel dos direitos culturais.

Entrevista com Farida Shaheed, da ONU. In: Revista Observatório Itaú Cultural/OIC, n. 11, jan./abr. 2011, São Paulo: Itaú Cultural, 2011.

\section{CROWDSOURCING.ORG. Crowdfunding}

Industry Report, 2013.Disponívelem: $<$ http:// www.crowdsourcing.org/editorial/2013cf-theCrowdfunding-industry-report/25107>. Acesso em: 23 mai. 2015.

CUNHA FILHO, F. H. Direitos culturais como direitos fundamentais no ordenamento jurídico brasileiro. Brasilia: Brasília Jurídica, 2000.

Teoria e prática da gestão cultural.

Fortaleza: Universidade de Fortaleza, 2002. 162 p.

Sistema Nacional da Cultura: Fato, Valor e Norma. Trabalho apresentado no III ENECULT, 2007 - Encontro de Estudos Multidisciplinares 
em Cultura, realizado entre os dias 23 e 25 de maio de 2007, na Faculdade de Comunicação/UFBA, Salvador-Bahia-Brasil 2007.

A questão jurídica no Brasil: direitos culturais no Brasil. In: Revista Observatório Itaú Cultural/OIC, n. 11, jan./abr. 2011, São Paulo: Itaú Cultural, 2011.

FIRJAN, S. Mapeamento da Indústria Criativa no Brasil. Rio de Janeiro,2014. Disponível em: $<\underline{\text { http:// }}$ www.firjan.org.br/economiacriativa/download/ mapeamento-industria-criativa-2014.pdf $>$ Acesso em: 23 mai. 2015.

DENZIN, N. K.; LINCOLN, Y. S. O planejamento da pesquisa qualitativa: teorias e abordagens. 2. ed. Porto Alegre: Artmed, 2006.

DOAN, A.; RAMAKRISHNAN, R.; HALEVY, A. Crowdsourcing systems on the World-Wide Web, Bib Sonomy, Communications of the ACM 54 (4): 2011, p. 86-96. Disponível em: $<$ http://cacm.acm. org/magazines/2011/4/106563-crowdsourcingsystems-on-the-world-wide-web/fulltext $>$ Acesso em: 23 mai. 2015.

FERNÁNDEZ, L. B. A salvaguarda do patrimônio imaterial na América Latina: uma abordagem de direitos, avanços e perspectivas. p. 14-39. In: CALABRE, L. Políticas culturais: teoria e práxis. São Paulo: Itaú Cultural; Rio de Janeiro: Fundação Casa de Rui Barbosa, 2011.

FREYRE, G. Casa Grande \& Senzala. 14. ed. Rio de Janeiro: José Olympio, 1969.

GONZÁLEZ, M. A. J. O planejamento cultural a partir da abordagem de redes. Um olhar baseado na experiência de formulação de políticas culturais na Colômbia, da Universidade de Antioquia. In: CALABRE, L. (Org.). Políticas culturais: teoria e práxis. São Paulo: Itaú Cultural; Rio de Janeiro: Fundação Casa de Rui Barbosa, 2011.

HILDEBRAND, T.; PURI, M.; ROCHOLL, J. Skin in the Game: Incentives in Crowdfunding. Social Science Research Network, May, 2010. Disponível em: $<$ http://papers.ssrn.com/sol3/papers.cfm?abstract $\underline{\mathrm{id}=1615483}>$ >. Acesso em: 23 mai. 2015.

HOWE, J. The Rise of Crowdsourcing. Wired, June, 2006. Disponível em: <http://www.wired.com/ wired/archive/14.06/crowds.html>. Acesso em: 23 mai. 2015.

Crowdsourcing: why the power of the crowd is driving the future of business. Wired, 2008.
LEHNER, O. M. A Literature Review and Research Agenda for Crowdfunding of Social Ventures. Article for the 2012 Research Colloquium on Social Entrepreneurship, 16th - 19th July, University of Oxford, Skoll Center of SAID Business School, 2012.

LIMA, C. Estratégias políticas no meio cultural. FACOM - Revista da Faculdade de Comunicação da FAAP, n. 12, São Paulo, $1^{\circ}$ sem. 2004. Disponível em: $<$ http://www.faap.br/revista faap/revista facom/ facom 12/facom 12.pdf > . Acesso em: 23 mai. 2015.

MACHADO, B. N. M. Os Direitos Culturais na Constituição Brasileira: Uma análise conceitual e política. In: CALABRE, L. Políticas culturais: teoria e práxis. (Org.). São Paulo: Itaú Cultural; Rio de Janeiro: Fundação Casa de Rui Barbosa, 2011.

MENDES, G. F. Direitos fundamentais e controle de constitucionalidade: estudos de direito constitucional. 3. ed. São Paulo: Saraiva, 2004.

MEYER-BISCH, P. A centralidade dos direitos culturais, pontos de contato entre diversidade e direitos humanos. In: Revista Observatório Itaú Cultural/OIC, n. 11, jan./abr. São Paulo: Itaú Cultural, 2011.

MIZRUCHI, M. S. Análise de Redes Sociais: avanços recentes e controvérsias atuais. Fórum, University of Michigan, 2006. Disponível em: $<\underline{\text { http:// }}$ www.scielo.br/pdf/rae/v46n3/v46n3a13.pdf $>$. Acesso em: 23 mai. 2015.

MOLES, A. A. Sociodinâmica da cultura. São Paulo: Perspectiva, 1974.

PAULA, L. Empreendedorismo cultural: A gestão de projetos culturais como empreendedorismo. Biblioteca Latino-Americana de Cultura e Comunicação, 1. São Paulo: USP, 2011. Disponível em: <http://myrtus.uspnet.usp.br/celacc/sites/ default/files/media/tcc/153-515-1-PB.pdf $>$. Acesso em: 23 mai. 2015.

RIBEIRO, D. Teoria do Brasil. Rio de Janeiro: Paz e Terra, 1972.

RICHARDSON, R. J. et al. Pesquisa social: métodos e técnicas. 3. ed. São Paulo: Atlas, 1999.

RUBINTON, B. J. Crowdfunding: Disintermediated Investment Banking. Social Science Research Network, Apr. 2011. Disponível em: < http://papers. ssrn.com/sol3/papers.cfm?abstract $\mathrm{id}=1807204>$. Acesso em: 23 mai. 2015. 
SILVA, A. B.; GODOI, C. K.; MELLO, R. B.

Pesquisa qualitativa em estudos organizacionais:

paradigmas, estratégias e métodos. São Paulo: Saraiva, 2006.

SOARES E SILVA, T. C. O Mecenato no Prêmio

Universidade: democratização ou alienação

da cultura? Revista Cambiassu, n. 4, jan./dez.

2008. Publicação Científica do Departamento de

Comunicação Social da Universidade Federal do

Maranhão (UFMA) - São Luís/MA, Ano XVIII.

SOUZA, C. Políticas Públicas: uma revisão da

literatura. Sociologias, Porto Alegre, ano 8, n. 16, jul./ dez. 2006, p. 20-45.

VALIATI, L.; FLORISSI, S. A problemática da

captação: relação entre os incentivos fiscais e a gestão dos recursos públicos na decisão privada da inversão cultural. VIII Encontro de Economia da Região Sul ANPEC SUL, Porto Alegre, 2005.

WU, C. Privatização da cultura: a intervenção corporativa na arte desde os anos 1980. Tradução Paulo Cezar Castanheira. São Paulo: Boitempo, 2006.

YÚDICE, G. A conveniência da cultura - usos da cultura na era global. Belo Horizonte: Editora UFMG, 2006. 